\title{
Different Roles of Direct and Indirect Frontoparietal Pathways for Individual Working Memory Capacity
}

\author{
Matthias Ekman, ${ }^{1,2}$ Christian J. Fiebach, ${ }^{1,3,4}$ Corina Melzer, ${ }^{2}{ }^{-}$Marc Tittgemeyer, ${ }^{2}$ and Jan Derrfuss ${ }^{1,2}$ \\ ${ }^{1}$ Radboud University Nijmegen, Donders Institute for Brain, Cognition and Behaviour, 6500 HE Nijmegen, The Netherlands, ${ }^{2}$ Max Planck Institute for \\ Neurological Research, 50931 Cologne, Germany, ${ }^{3}$ Department of Psychology, Goethe University Frankfurt, 60323 Frankfurt am Main, Germany, and \\ ${ }^{4}$ Center for Individual Development and Adaptive Education, 60486 Frankfurt am Main, Germany
}

The ability to temporarily store and manipulate information in working memory is a hallmark of human intelligence and differs considerably across individuals, but the structural brain correlates underlying these differences in working memory capacity (WMC) are only poorly understood. In two separate studies, diffusion MRI data and WMC scores were collected for 70 and 109 healthy individuals. Using a combination of probabilistic tractography and network analysis of the white matter tracts, we examined whether structural brain network properties were predictive of individual WMC. Converging evidence from both studies showed that lateral prefrontal cortex and posterior parietal cortex of high-capacity individuals are more densely connected compared with low-capacity individuals. Importantly, our network approach was further able to dissociate putative functional roles associated with two different pathways connecting frontal and parietal regions: a corticocortical pathway and a subcortical pathway. In Study 1, where participants were required to maintain and update working memory items, the connectivity of the direct and indirect pathway was predictive of WMC. In contrast, in Study 2, where participants were required to maintain working memory items without updating, only the connectivity of the direct pathway was predictive of individual WMC. Our results suggest an important dissociation in the circuitry connecting frontal and parietal regions, where direct frontoparietal connections might support storage and maintenance, whereas subcortically mediated connections support the flexible updating of working memory content.

Key words: basal ganglia; diffusion MRI; network analysis; prefrontal cortex; working memory capacity

Significance Statement

Using diffusion MRI and network analysis, we found that the capacity of healthy individuals to temporally maintain information in working memory was related to a cortical pathway connecting frontal and parietal regions. The updating of working memory content, on the other hand, additionally involved a subcortical pathway connecting frontal and parietal regions via thalamus and basal ganglia. These results suggest that the two anatomical pathways serve different functional roles for working memory.

\section{Introduction}

Humans and nonhuman primates have developed a remarkable capacity to store and manipulate information "online." This process, referred to as working memory, is fundamental for many

\footnotetext{
Received April 4, 2014; revised Jan. 14, 2016; accepted Jan. 16, 2016.

Author contributions: M.E. and J.D. designed research; M.E. and J.D. performed research; M.E. and C.M. contributed unpublished reagents/analytic tools; M.E. analyzed data; M.E., C.J.F., M.T., and J.D. wrote the paper.

This work was supported by The Netherlands Organization for Scientific Research VIDI Grant 45209006 to C.J.F., C.J.F. was supported by ERC Consolidator Grant 617891 and the LOEWE initiative of the state of Hesse. M.T. was supported by the German Research Foundation in the Transregional Collaborative Research Center 134 and in the clinical research unit KF0-219. J.D. was supported by the German Research Foundation Grant DE 1141/2-1. We thank Doris Keye for providing us with the working memory task; and Viola Vogt for help with data acquisition.

The authors declare no competing financial interests.

Correspondence should be addressed to Dr. Matthias Ekman, Radboud University Nijmegen, Donders Institute for

Brain, Cognition and Behaviour, 6500 HE Nijmegen, The Netherlands. E-mail: matthias.ekman@gmail.com.

J. Derrfuss' current address: School of Psychology, University of Nottingham, United Kingdom.

DOI:10.1523/JNEUROSCI.1376-14.2016

Copyright $\odot 2016$ the authors $\quad 0270-6474 / 16 / 362894-10 \$ 15.00 / 0$
}

perceptual and cognitive abilities (Fukuda et al., 2010; Johnson et al., 2013) and is closely linked to general intelligence (Conway et al., 2003). The capacity of working memory (WMC) varies substantially across individuals (Cowan, 2001; Luck and Vogel, 2013), but the neural correlates of individual differences in WMC are at present only poorly understood.

Recent studies using fMRI and EEG suggest that differences in WMC can be partly attributed to differences in attentional processes involved in the selection of relevant and filtering of irrelevant information (Vogel and Machizawa, 2004; McNab and Klingberg, 2008; Luck and Vogel, 2013). Irrelevant information consumes unnecessary capacity, and it has been shown that lowcapacity individuals tend to encode irrelevant information to a greater extent than high-capacity individuals (Vogel et al., 2005; Luck and Vogel, 2013). The effectiveness of filtering out irrelevant information thus may form a critical basis for the capacity limit of working memory (Kane and Engle, 2002; McNab and 
Klingberg, 2008). The prefrontal cortex (PFC) forms the top of a hierarchy that, on the one hand, enables robust maintenance (Cohen et al., 1997; Curtis and D'Esposito, 2003) and selective boosting of WM storage in posterior parietal cortex (PPC) (Edin et al., 2009) and, on the other hand, allows for filtering of WM representations via frontostriatal connections (Alexander et al., 1986), where the basal ganglia and the thalamus act as a gate that support the flexible updating of WM contents in a taskdependent manner (Frank et al., 2001; O'Reilly and Frank, 2006; $\mathrm{McNab}$ and Klingberg, 2008). This interpretation is in line with the predominant view of the PFC as a key region for executive control (D'Esposito et al., 1995; Miller and Cohen, 2001; Baddeley, 2003) and integrates well with the proposal that individual differences in WMC are a function of differences in the efficiency of executive control processes (Engle and Kane, 2004).

Studies exploring the structural correlates of WMC using diffusion MRI (dMRI) linked higher WMC to higher white matter "integrity" in frontoparietal regions (Nagy et al., 2004; Klingberg, 2006; Takeuchi et al., 2010). However, it is an open question how specifically these structural properties contribute to individual differences in WMC. One possible explanation is that higher white matter "integrity" improves information processing capacities of the brain in an unspecific manner, and thereby allows for faster information transfer and enhanced communication between frontal and parietal brain regions (Nagy et al., 2004; Karlsgodt et al., 2008). Alternatively, the anatomical basis for individual differences in WMC may be grounded in different contributions of two anatomical pathways connecting frontal and posterior parietal regions, a direct corticocortical pathway connecting prefrontal and parietal regions via the superior longitudinal fasciculus (Klingberg, 2006), associated with maintenance and boosting of WM storage in parietal regions (Edin et al., 2009), and an indirect pathway via the striatum and thalamus (Alexander et al., 1986; Clower et al., 2005) that was implicated in gating and flexible updating of WM content (Frank et al., 2001; McNab and Klingberg, 2008).

To test this hypothesis, we measured participants' WMC using two different working memory tasks, and examined the anatomical contribution of direct versus indirect anatomical pathways to WMC differences using dMRI. The WM task in Study 1 involves maintenance and frequent updating of to-be-remembered items and should therefore rely on both the direct and indirect pathways. In contrast, Study 2 involves maintenance of to-be-remembered items but no updating and should therefore rely exclusively on the direct pathway.

\section{Materials and Methods}

Participants. Healthy volunteers participated with informed consent in accordance with the local ethics committee of the University Hospital in Cologne, Germany (Study 1: $N=70,32$ female, age $25 \pm 3$ years, mean \pm SD; Study 2 : $N=109,56$ female, age $25 \pm 4$ years). Study 1 and Study 2 are independent samples (i.e., none of the participants of Study 1 participated in Study 2 and vice versa). An independent set of 20 participants (10 female, age $24 \pm 2$ years) completed the behavioral tasks from Study 1 and Study 2, without structural imaging, to assess the similarity of the two different WM tasks.

Working memory tasks. Before image acquisition, participants performed a working memory task that was used to quantify individual WMC. In the WMC task of Study 1, each trial involved the presentation of 2-7 numbers between 1 and 9 , on a $3 \times 3$ grid (Wilhelm and Oberauer, 2006). Participants were instructed to maintain and update these numbers $(+1 /-1)$ based on instructions indicated by an upward or downward pointing arrow, respectively (Fig. 1A). By the end of a trial, a question mark appeared in one of the cells, and participants had to enter the resulting updated number using a keyboard. Working memory span was calculated using the partial credit unit scoring method, in which credit is given to partly correct items, resulting in WMC scores in the range between 0 and 1 (Conway et al., 2005).

The task used in Study 2 was a digit forward span test from the Wechsler Adult Intelligence Scale (WAIS-IV) (Wechsler, 2009). Here, participants had to remember and recall (interval: $5 \mathrm{~s}$ ) a sequence of verbally presented digits (between 1 and 9; compare Fig. $1 B$ ). The sequences started with 2 items and increased in difficulty up to 10 items. If a sequence was correctly repeated after the delay, the number of items for the next sequence increased by 1 . If a sequence was incorrectly repeated, a different sequence of the same length was presented. The task concluded when both sequences of a given length were incorrect. Raw WM scores were calculated by adding the number of correctly recalled items. For the final pair of sequences (i.e., the sequences that were both incorrect), the sequence with more correct items was taken into account. For example, if a participant correctly recalled at least one sequence up to a load of 4 , they would receive 9 points $(2+3+4)$ for these sequences. For the final sequences with a load of 5 , they might have received 4 points for the first sequence and 3 points for the second. In this case, the first sequence would be taken into account, and the final raw WM score would be 13 points. The points were transformed into scaled WMC scores, ranging from 0 to 19 , according to age-specific norm tables of the standardized test manual of the WAIS-IV.

Importantly, the working memory tasks in Study 1 and Study 2 differed with respect to component processes. The complex WM span task in Study 1 required participants to maintain and update information, whereas the forward span task in Study 2 only required maintenance. As explained in the introduction, we hypothesized that these component processes would rely on dissociable white matter pathways (Fig. 1C).

Image acquisition. High-resolution T1-weighted images were acquired using a Siemens 3T Trio scanner (12-channel array head coil; maximum gradient strength $40 \mathrm{mT} / \mathrm{m})$ with a whole-brain FOV $($ MDEFT3D; TR = $1930 \mathrm{~ms}, \mathrm{TE}=5.8 \mathrm{~ms}, 128$ sagittal slices, resolution $=1 \times 1 \times 1.25 \mathrm{~mm}^{3}$, flip angle $\left.=18^{\circ}\right)$. Diffusion-weighted data were collected using spin-echo EPI (twice refocused spin-EPI; TR $=9000 \mathrm{~ms}, \mathrm{TE}=87 \mathrm{~ms}, 72$ axial slices, resolution $=1.7 \times 1.7 \times 1.7 \mathrm{~mm}^{3}$ ). Diffusion weighting was isotropically distributed along 60 directions (b-value $1000 \mathrm{~s} / \mathrm{mm}^{2}$ ). Finally, seven images without diffusion weighting were acquired at the beginning and after each block of 10 diffusion-weighted images, providing an anatomical reference for motion artifact correction. To increase the signal-tonoise ratio of the diffusion-weighted images, the arithmetic mean across three consecutive scanning sessions was computed. Image acquisition parameters were the same for Study 1 and Study 2.

Node definition. Network nodes were constructed by parcellating 116 regions from the automated anatomical labeling atlas (Tzourio-Mazoyer et al., 2002) into 1040 approximately equally sized regions (Fig. $2 A$; voxels per region: $33.5 \pm 6.8$, mean $\pm S D$; voxel size: $\left.2 \times 2 \times 2 \mathrm{~mm}^{3}\right)$. This map was registered from the MNI space to each participant's native dMRI space, preserving discrete values using a nearest neighbor interpolation method (Gong et al., 2009; Cao et al., 2013). The computational costs of the network computation increase exponentially with the number of nodes; therefore, the number of 1040 nodes appeared to be a good compromise between reasonable spatial resolution and computational feasibility. For each participant, the estimation of the local connectivity distribution took $\sim 24 \mathrm{~h}$, and the probabilistic tractography for the 1040 seed regions took $\sim 260 \mathrm{~h}$ using a single-core central processing unit.

White matter tractography. We performed probabilistic tractography using FSL FDT, version 3.0 (Behrens et al., 2003) with default parameters. From each of the 1040 seed regions, $5000 \times n$ streamlines were sampled, where $n$ is the number of voxels in one region (Fig. 2A). The resulting connectivity probability for two regions $i$ and $j$ is given by the number of fibers starting in region $i$ and passing through region $j$ divided by $5000 \times n$. Because of the nature of the probabilistic tracking, the resulting connectivity probabilities between two regions (i.e., $\mathrm{a}_{i j}$ and $\mathrm{a}_{j i}$ ) is not necessarily the same, albeit highly correlated. We defined an undirected connectivity matrix A by averaging both probabilities for every pair of nodes (Fig. 2B). Notably, all further analyses were performed on the weighted connectivity matrix, taking into account the probabilistic 
A Study $1(\mathrm{~N}=70)$

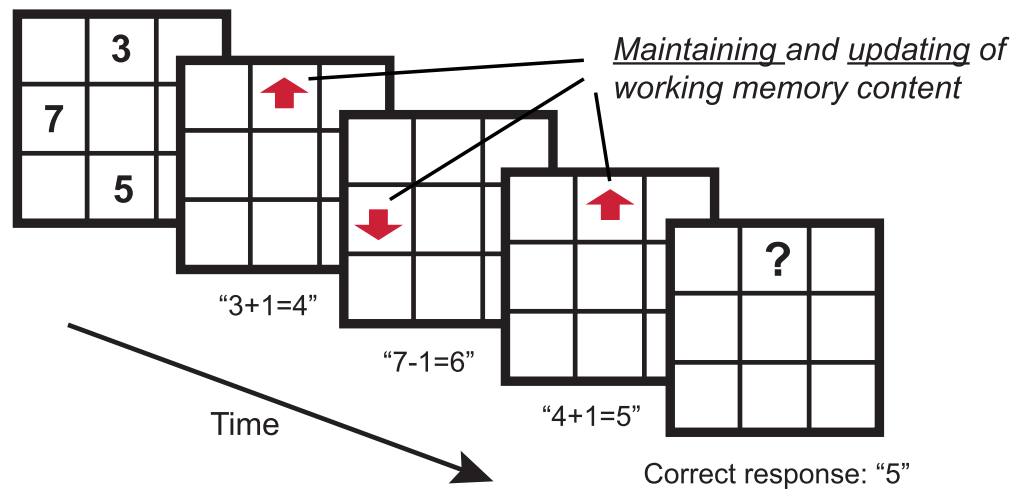

B

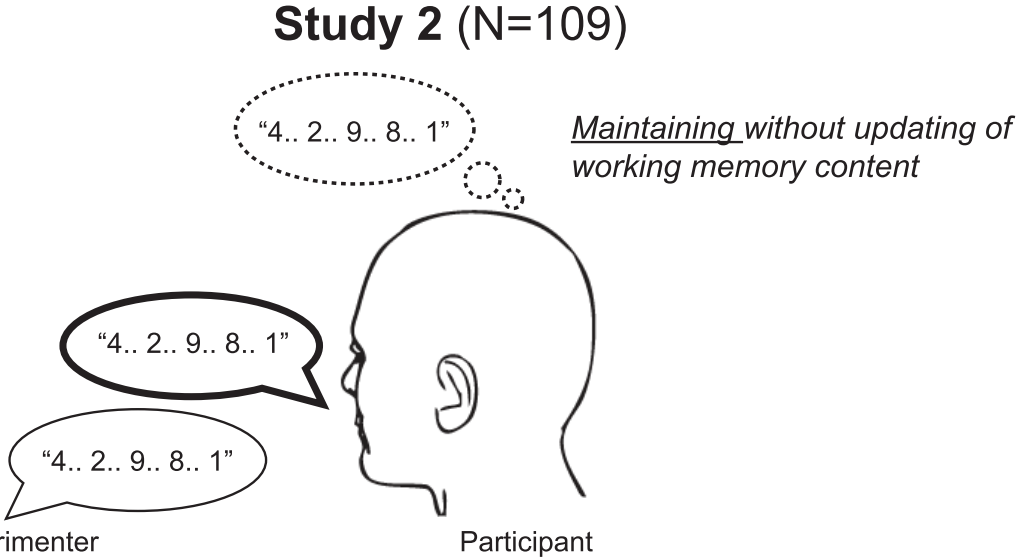

\section{Study 1}

Working memory task with updating

Study 2

Working memory task without updating

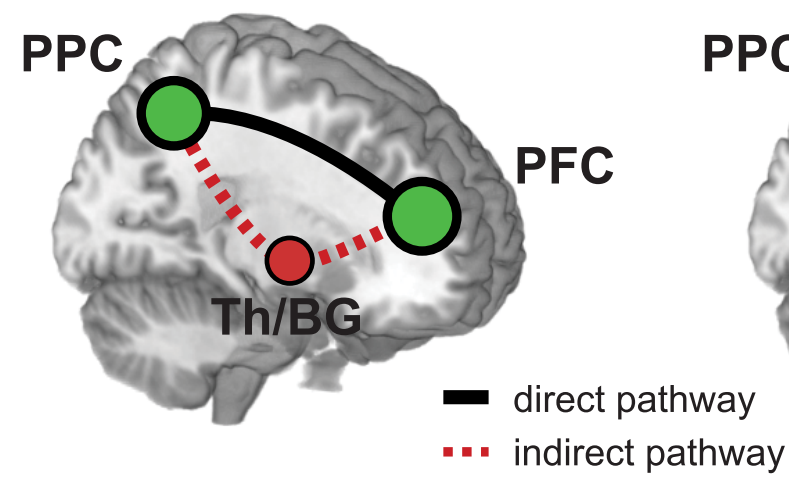

Figure 1. Working memory tasks and outline of expected results. Working memory tasks used in (A) Study 1 ("maintenance and updating") and (B) Study 2 ("maintenance"). C, Expected dissociation of the functional roles of two anatomical pathways connecting frontal and parietal brain regions. Based on previous fMRI results, we predicted that individual WMC in Study 1 (involving WM updating) depends on a direct corticocortical pathway and an indirect subcortically mediated pathway. In contrast, for Study 2 involving only WM maintenance, we predicted that individual WMC depends only on the direct pathway (see Materials and Methods). Th/BG, Thalamus/basal ganglia.

nature of the tractography results and circumventing the problem of finding an arbitrary threshold when converting weighted into unweighted matrices (Cao et al., 2013; de Reus and van den Heuvel, 2013).

Network analysis. Our first goal was to identify brain regions in which the white matter connectivity correlated with WMC. To achieve this, we used a graph-theoretical measure of node-specific network centrality that quantifies the connectivity of a single node in one value. In a second step, we sought to further quantify the connectivity of the identified brain regions using dMRI tractography. For each participant, based on the white matter network A, we calculated the weighted degree for each network node. Degree is a network centrality measure that reflects how well a certain node is connected to all other nodes in the network and that has been shown to be a sensitive (Lohmann et al., 2010; Ekman et al., 2012) and reliable (Zuo et al., 2012) metric for the characterization of 


\section{A}

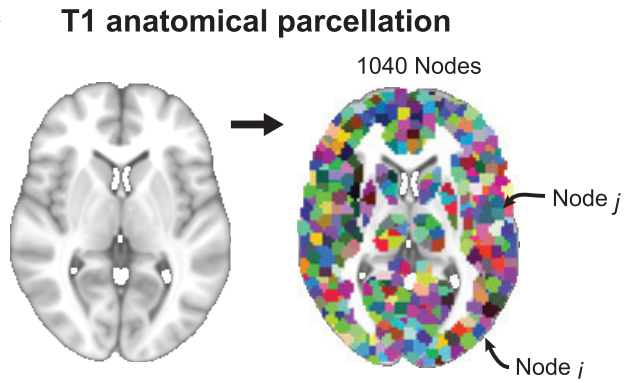

Probabilistic tractography

B

\section{C}
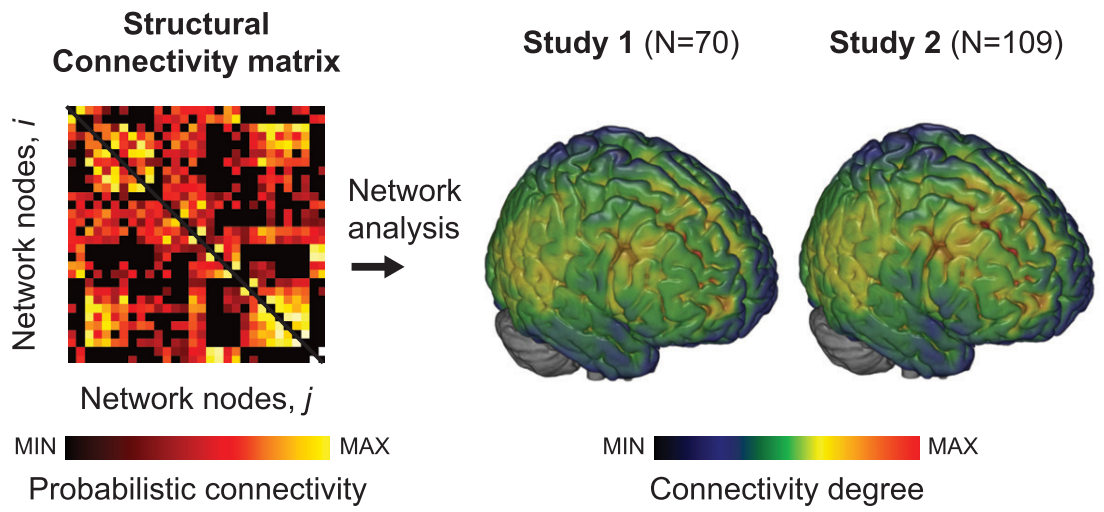

Figure 2. Illustration of the pipeline to construct the large-scale white matter structural networks from diffusion MRI. $A$, Individual T1-weighted images were segmented into 1040 cortical and subcortical network nodes, and the connectivity probability with all other nodes was estimated using probabilistic tractography (see Materials and Methods). $\boldsymbol{B}$, Individual connectivity matrices, reflecting the probability that any two nodes are connected, were used to calculate the degree centrality for each node. Degree centrality quantifies the "connectedness" of an individual node with all other nodes in the network (see Materials and Methods). C, Group-averaged degree centrality maps projected onto the gray matter surface, separately for each study.

human brain networks. Further, degree-based connectivity measures have been found to yield robust results for different network construction methods and different node resolutions (Zhong et al., 2015). The weighted degree $k$ of a node $i$ is defined as follows:

$$
k(i)=\sum_{j \in N} a_{i j}
$$

Individual degree maps were registered to the MNI151 $1 \mathrm{~mm}$ template and spatially filtered (FWHM $=5 \mathrm{~mm}$ ) to account for anatomical variability across participants. Group-averaged degree maps for Study 1 and Study 2 are shown in Figure 2C.

Predicting WMC from network connectivity. A GLM was used to predict WMC from degree maps (i.e., for individual voxels) across participants, separately for Study 1 and Study 2. The GLM included age and gender as variables of no interest. Resulting statistical maps were corrected for multiple comparisons using cluster correction with FSL's cluster command $(z=2.33$, cluster significance threshold, $p<0.05)$ and projected to the inflated gray matter surface (Fig. 3).

Probing different roles for frontoparietal pathways. Previous studies have highlighted the involvement of a frontostriatal pathway, for the attentional control and filtering of working memory storage in parietal regions (Frank et al., 2001; McNab and Klingberg, 2008). In contrast, direct frontoparietal connections were associated with maintenance and boosting of working memory representations in posterior areas via excitatory input from the PFC (Edin et al., 2009). Based on these results from functional imaging and modeling, we predicted that WMC in Study 1 , involving maintenance and updating of WM content, should rely both on the direct frontoparietal pathway, supporting maintenance, and the indirect pathway, supporting flexible updating. In contrast, we predicted that WMC in Study 2, involving maintenance but no updating of WM content, should only rely on the direct pathway, but not on the indirect pathway.

To test our predictions, we performed probabilistic tractography separately for the direct and indirect frontoparietal pathway. First, three spherical ROIs (right PFC and bilateral $\mathrm{PPC}$; radius $=9 \mathrm{~mm}$ ) were created at the joint peak of the statistical maps from Study 1 and Study 2 (Fig. 4A). Second, probabilistic tracking was performed between the PFC and the PPC ROIs using FSL's probtrackx "matrix option." Tracking from the spherical ROIs ensures that PFC and PPC have the same volume for all participants and across studies and, therefore, rules out that the tractography results are biased by volume differences of the relevant regions.

To separate direct and indirect pathways, the probabilistic tracking was repeated twice. To quantify the connectivity of the indirect pathway, thalamus and basal ganglia were specified as "waypoint mask" for the tracking and only streamlines passing these subcortical structures were taken into account for estimating the connectivity distribution (Fig. $4 B, C$ ). For the quantification of the direct pathway, thalamus and basal ganglia were used as "exclusion mask," discarding streamlines that entered the mask. Thalamus and basal ganglia were determined for individual participants using FSL's FAST (Zhang et al., 2001) and registered to the native dMRI space.

Finally, frontoparietal connectivity for the direct and indirect pathways was quantified by dividing the number of streamlines found between PFC and PPC by the total number of sampled streamlines. Resulting connectivity values cannot be directly interpreted as "strength" of the connection but reflect a connectivity probability ranging from 0 (reflecting low connection probability) to 1 (reflecting high connection probability).

A GLM was used to predict individual WMC from the two frontoparietal connectivity estimates (i.e., direct and indirect pathway) and also included age and gender as variables of no interest. Combining these predictors in one model allows us to quantify and contrast the relative contribution of the direct and indirect pathway to WMC. We used nonparametric permutation tests to test for significant differences of the regression weights from 0 . To this end, WMC scores were randomly permuted, and we recalculated the GLM analysis with 10,000 permutations. The $p$ value was given by the fraction of shuffles in which the original regression weight was exceeded by the regression weight for the shuffled data. Further, post hoc contrasts were performed to test for differences in regression weights for the direct and indirect pathways. All results were corrected for multiple comparisons using false discovery rate (FDR) $(q=0.05)$.

\section{Results}

\section{Behavioral results}

Individual working memory span varied widely across participants (Study 1, 0.71 \pm 0.09, mean $\pm \mathrm{SD}$; range 0.49-0.92; Study $2,11.07 \pm 2.95$, mean $\pm \mathrm{SD}$; range $5-19)$. No significant correlation was observed between WMC and age (Study $1, r=0.06$, $p=0.64$; Study 2, $r=-0.05, p=0.62$ ), and no significant difference was found between male and female participants (independent $t$ test, Study 1, $t_{(68)}=0.51, p=0.61$; Study 2, $t_{(107)}=$ $-0.12, p=0.90)$. No significant differences were found between Study 1 and Study 2 with respect to age (independent $t$ test, 

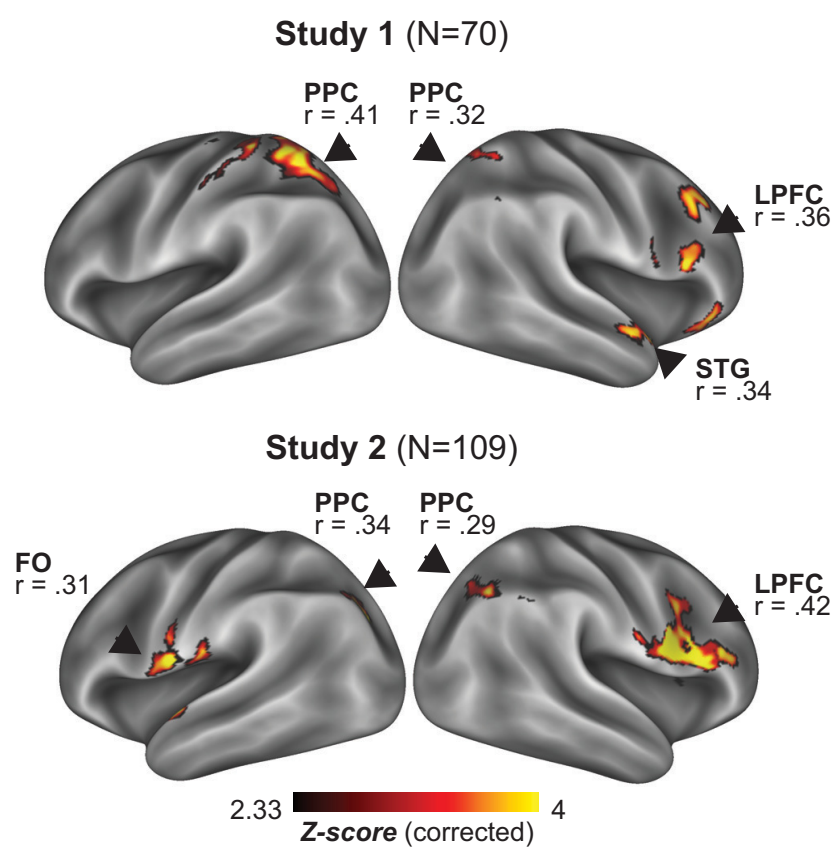

Figure 3. White matter connectivity correlates with individual WMC. Significant clusters from the whole-brain analysis show a positive correlation in the right lateral PFC, bilateral PPC, and right STG (Study 1, top). Even though the visualization suggests multiple PFC clusters, these are connected and indeed form a single activation cluster. Significant clusters from Study 2 (bottom) show a positive correlation in the right lateral PFC, bilateral PPC, and F0 (all $p<0.05$, corrected for multiple comparisons). LPFC, Lateral prefrontal cortex; STG, superior temporal gyrus; F0, frontoparietal operculum.

$\left.t_{(177)}=-0.88, p=0.38\right)$ and gender $\left(\chi^{2}\right.$ test, $\chi^{2}=0.16, p=$ $0.69)$. Twenty additional participants, for whom we collected behavioral data from both WM tasks, were used to estimate the similarity of WMC scores between studies. WMC scores from Study 1 and Study 2 were significantly correlated $(r=0.53, p=$ 0.02 ), which indicates that both tasks capture similar WM constructs. However, the correlation of $r=0.53$ is considerably lower than the specified retest reliability for the WAIS span test used in Study $2(r=0.79)$, which most likely reflects the fact that both tasks focus on different component processes of WM (i.e., specifically the absence of an updating component in Study 2).

\section{Network centrality of frontal and parietal regions predict individual WMC}

Our main question was whether white matter structural network properties are predictive of individual WMC. To answer this question, we used probabilistic tractography and graph analysis to quantify the network centrality of 1040 brain regions. The spatial structure of the group-averaged degree centrality maps from Study 1 and Study 2 were highly correlated (in the sense of a correlation of degree centrality values between the two samples across voxels), suggesting that degree centrality reflects fundamental quantitative properties of white matter connectivity $(r=$ 0.99, $p<0.001)$.

A whole-brain linear regression analysis was used to predict WMC based on network centrality values derived from diffusion MRI-based tractography (see Materials and Methods). In Study 1 , network centrality was predictive of individual WMC in the right lateral PFC (peak: $r=0.36$ ), including the posterior inferior frontal gyrus and the posterior middle frontal gyrus (Fig. 3; Table 1 ), the bilateral posterior parietal cortex (left peak: $r=0.41$; right peak: $r=0.32$ ), and the right superior temporal gyrus (peak: $r=$
0.34 ; all $p<0.05$, corrected for multiple comparisons using cluster correction). The cluster in the superior temporal gyrus was continuous with another cluster in the inferior frontal gyrus, lateral orbital gyrus, and posterior orbital gyrus. In Study 2, network centrality was predictive of individual WMC in the same set of brain regions, that is, the right lateral PFC (peak: $r=0.42$ ), including the posterior inferior frontal gyrus, inferior precentral gyrus, and extending to the inferior frontal junction (Derrfuss et al., 2005), and the bilateral posterior parietal cortex (left peak: $r=$ 0.29 , right peak: $r=0.34$ ). A significant correlation in Study 2 was further found in the left frontoparietal operculum, extending to the superior temporal gyrus (peak: $r=0.31$; all $p<0.05$, corrected for multiple comparisons using cluster correction; Fig. 3; Table 1). Participants' age and gender (which were included as variables of no interest into the GLMs) showed no significant correlation with degree centrality (all $p>0.1$, corrected for multiple comparisons using cluster correction). Statistical maps from Study 1 and Study 2 overlapped in the right PFC and in the bilateral PPC (Fig. 4A; Table 1), presenting converging evidence from two independent studies that frontoparietal white matter connectivity is positively correlated with individual WMC.

\section{Distinct anatomical circuits for frontoparietal connectivity}

Expanding on these results, we sought to dissociate the functional relevance of two distinct anatomical pathways connecting frontoparietal regions, namely, a direct corticocortical pathway (Klingberg, 2006) and an indirect pathway via subcortical regions (Clower et al., 2005). Previous studies have suggested that a frontostriatal network is involved in controlling the access to working memory storage in parietal and sensory regions (Pasternak and Greenlee, 2005) and in exerting attentional control to filter irrelevant information that consumes unnecessary capacity (Frank et al., 2001; O'Reilly and Frank, 2006; McNab and Klingberg, 2008). Direct corticocortical connections between frontal and parietal cortex, on the other hand, were associated with WM maintenance and with the boosting of working memory representations in posterior areas via excitatory input from the PFC (Edin et al., 2009).

To test whether these results can be extended to white matter network connectivity, we quantified the relative contributions of the direct and indirect pathways to individual WMC using multiple linear regression (see Materials and Methods). To this end, we took the overlapping PFC and PPC regions from Study 1 and Study 2 (Fig. 4A; Table 1) as starting points to perform probabilistic tractography and estimated the connectivity between these regions via the direct and indirect pathway (Fig. $4 B, C$ ), respectively. Here, the direct pathway crosses the corpus callosum and follows approximately the superior longitudinal fasciculus from the right PFC to the bilateral PPC. The indirect pathway routes from the right PFC to the bilateral PPC via basal ganglia (including globus pallidus and striatum) and thalamus. Importantly, our results showed that the probabilities of frontoparietal connections for the direct and indirect pathways were not significantly correlated (Study 1, $r=-0.05, p=0.70$; Study 2, $r=-0.09, p=$ 0.34 ), indicating that the two pathways might independently contribute to individual WMC. No significant differences were found between Study 1 and Study 2 for the connectivity estimates of the direct pathway (independent $t$ test, $t_{(177)}=0.11, p=0.91$ ) and the indirect pathway (independent $t$ test, $t_{(177)}=-1.11, p=$ 0.27 ), suggesting that there were no systematic differences between the two populations.

In Study 1, involving maintenance and updating, both the direct pathway $\left(t_{(66)}=3.56, p=7.1 \times 10^{-4}\right)$ and the indirect 
A

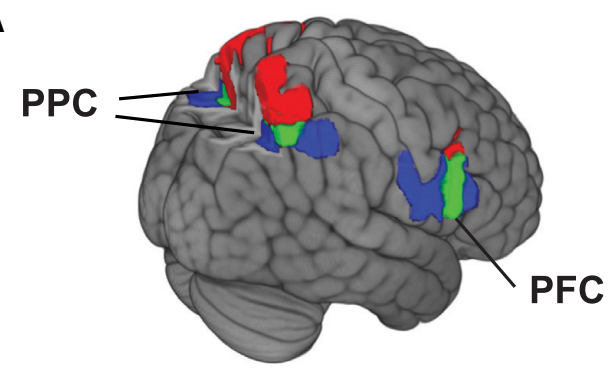

Study 1

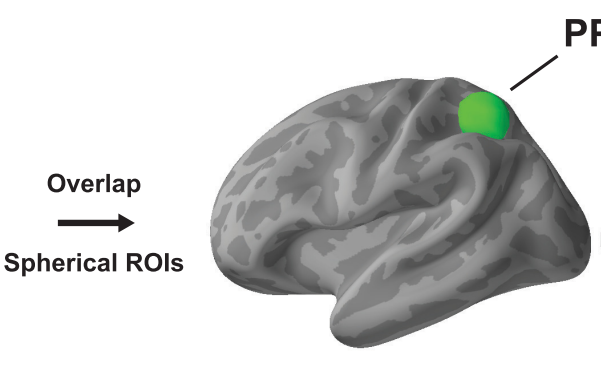

PPC

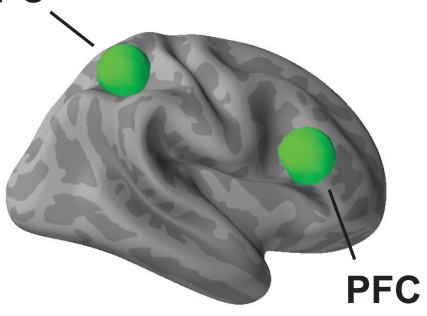

C

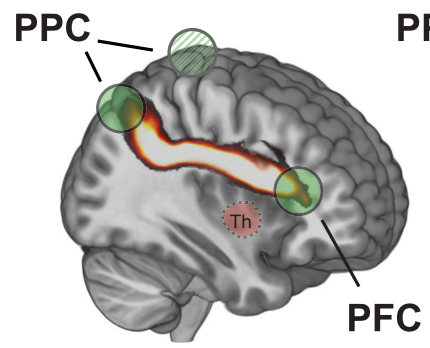

Direct pathway Th/BG exclusion

Study $2(N=109)$

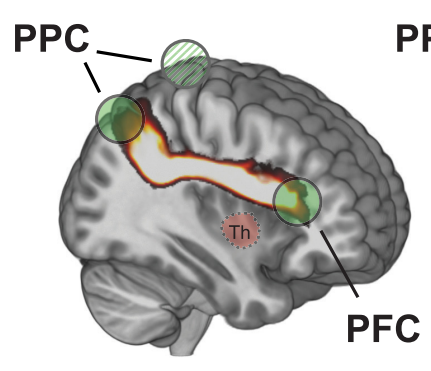

Direct pathway Th/BG exclusion
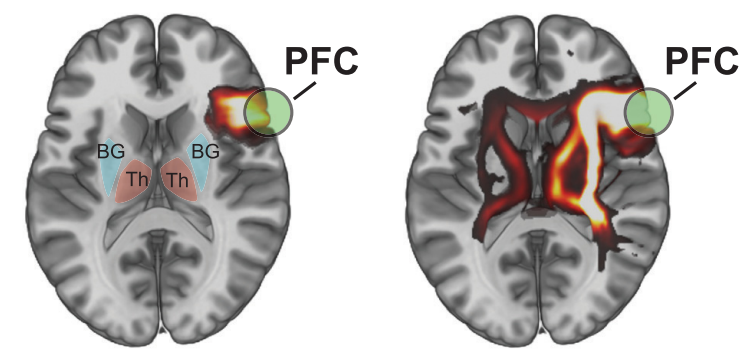

MAX

Probabilistic connectivity

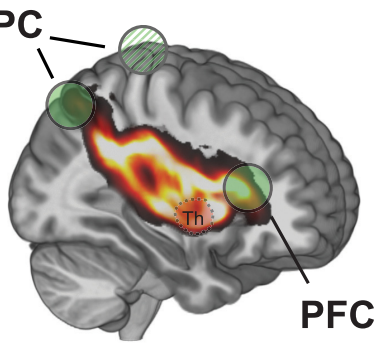

Indirect pathway via $\mathrm{Th} / \mathrm{BG}$
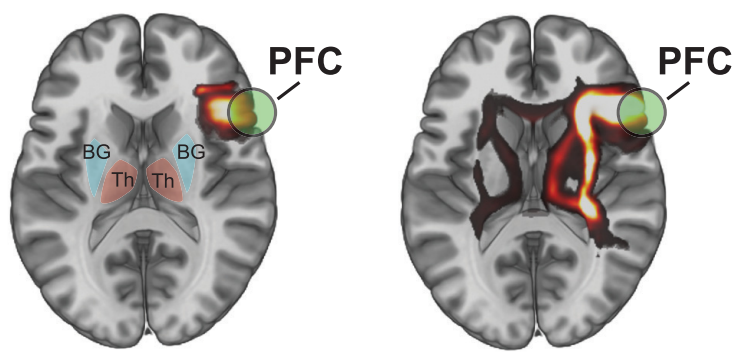

Probabilistic connectivity

Figure 4. Probing different roles of frontoparietal pathways for individual WMC. A, Brain regions where white matter connectivity was significantly correlated with individual WMC in Study 1 (red) and Study 2 (blue). The overlap (green) was used to create spherical ROls (radius $=9 \mathrm{~mm}$ ). B, Probabilistic tractography was performed between the right PFC and bilateral PPC ROIs. Shaded ROI represents the left-hemispheric PPC. Connectivity of the direct pathway (left) was estimated by excluding streamlines that passed through thalamus (Th) and basal ganglia (BG). Connectivity for the indirect pathway (right) was estimated by counting only streamlines that passed through Th and BG (see Materials and Methods). Shown is the local group-averaged connectivity distribution. C, Same as in B for Study 2. Th, Thalamus; BG, basal ganglia.

pathway $\left(t_{(66)}=2.54, p=0.014\right)$ revealed a significant and positive association with individual WMC (Fig. 5). In contrast, results for Study 2, involving maintenance but no updating of WM content, indicated that only the direct pathway $\left(t_{(105)}=3.28, p=\right.$ $1.4 \times 10^{-3}$ ) had a significant and positive association with individual WMC. Regression weights for the indirect pathway were not significantly different from $0\left(t_{(105)}=0.28, p=0.78\right)$. Contrasting the relative contributions of the two pathways within each study showed that the direct pathway has a significantly stronger contribution to individual WMC compared with the indirect pathway both in Study $1\left(t_{(68)}=2.40, p=0.019\right)$ and Study $2\left(t_{(107)}=3.15, p=2.1 \times 10^{-3}\right)$. All $p$ values were corrected for multiple comparisons using FDR $(q=0.05)$.

Finally, the data from Study 1 and Study 2 were combined to perform post hoc analyses to test statistically the difference in involvement of the indirect pathway between the two studies (i.e., in the form of study $\times$ pathway interactions). The study $\times$ indirect pathway interaction was significant $\left(F_{(1,171)}=3.99, p=\right.$ 0.04 ), confirming our hypothesis that the indirect pathway was only predictive of WMC when the task required maintenance and frequent updating of WM content (i.e., as in Study 1). In contrast, the study $\times$ direct pathway interaction was not significant $\left(F_{(1,171)}=0.84, p=0.36\right)$, highlighting the relevance of the direct pathway for both working memory tasks.

Together, these results indicate that high-capacity individuals showed higher frontoparietal white matter structural connectivity than individuals with lower WM capacity. Further, the analysis of two anatomical pathways connecting frontal and parietal regions revealed that the direct corticocortical pathway had a relatively stronger influence on individual WMC compared with the indirect subcortically mediated pathway. Importantly, the indirect pathway, in previous functional neuroimaging studies 
Table 1. Regions correlated with working memory capacity ${ }^{a}$

\begin{tabular}{|c|c|c|c|c|c|c|}
\hline & $\begin{array}{l}\text { Volume } \\
\left(\mathrm{mm}^{3}\right)\end{array}$ & Hemisphere & $x$ & $y$ & $z$ & $z$ valu \\
\hline \multicolumn{7}{|l|}{ Study 1} \\
\hline $\begin{array}{l}\text { Lateral PFC (posterior IFG, posterior } \\
\text { middle frontal gyrus) }\end{array}$ & 5812 & $\mathrm{RH}$ & 50 & 22 & 20 & 3.1 \\
\hline PPC & 4292 & $\mathrm{RH}$ & 33 & -55 & 59 & 2.9 \\
\hline PPC & 11,759 & $\mathrm{LH}$ & -31 & -52 & 60 & 3.4 \\
\hline Superior temporal gyrus & 6053 & $\mathrm{RH}$ & 56 & 12 & -13 & 3.8 \\
\hline IFG, LOG, POG & & $\mathrm{RH}$ & 47 & 29 & -15 & 2.9 \\
\hline \multicolumn{7}{|l|}{ Study 2} \\
\hline $\begin{array}{l}\text { Lateral PFC (posterior IFG, inferior } \\
\text { precentral gyrus, inferior } \\
\text { frontal junction) }\end{array}$ & 10,327 & $\mathrm{RH}$ & 50 & 26 & 16 & 4.5 \\
\hline PPC & 1872 & $\mathrm{RH}$ & 40 & -59 & 46 & 3.47 \\
\hline PPC & 2351 & $\mathrm{LH}$ & -31 & -68 & 42 & 3.7 \\
\hline Frontoparietal operculum & 3950 & LH & -55 & -16 & 18 & 4.3 \\
\hline \multicolumn{7}{|l|}{ Overlap Study 1 and Study 2} \\
\hline Lateral PFC (posterior IFG) & 3808 & $\mathrm{RH}$ & 52 & 22 & 18 & 0 \\
\hline PPC & 1215 & $\mathrm{RH}$ & 41 & -55 & 45 & 0 \\
\hline PPC & 580 & LH & -41 & -55 & 44 & 0 \\
\hline
\end{tabular}

${ }^{a}$ The peak coordinates are given in MNI152 $1 \mathrm{~mm}$ space. IFG, Inferior frontal gyrus; LOG, lateral orbital gyrus; POG, posterior orbital gyrus; RH, right hemisphere; $\mathrm{LH}$, left hemisphere.

associated with flexible updating of WM content, was only significantly correlated with WMC when the task required updating of WM content (i.e., in Study 1 but not in Study 2). This distinction points to a dissociation of the two anatomical pathways with respect to their functional relevance.

\section{Discussion}

Working memory has been associated with a distributed network of brain regions in humans (Jonides et al., 1993; Cohen et al., 1997; Courtney et al., 1998; Pessoa et al., 2002; Rottschy et al., 2012; Nee et al., 2013) and nonhuman primates (Fuster, 1990; Goldman-Rakic, 1996). Theories of working memory (Baddeley, 2003) suggest that this network can be broadly divided into areas that maintain and store information and areas that contribute to the top-down control and manipulation of working memory contents. Here we present evidence that the way these two systems are interconnected contributes to individual differences in WMC.

Investigating large-scale white matter connectivity networks, we found that the connectivity of the PFC and PPC is positively correlated with individual WMC. The positive correlation of PFC connectivity with individual WMC is consistent with the general notion of the PFC as an important control region for working memory (Kane and Engle, 2002; Curtis and D'Esposito, 2003; Nee et al., 2013). Multiple studies have shown that the PFC has connections to large parts of the cortex, suggesting that PFC is in an ideal position to integrate and coordinate information processing in various brain regions. Our findings are in line with this interpretation, as higher network centrality for high-capacity individuals might facilitate these top-down processes (Kane and Engle, 2002).

The PFC is also strongly connected via multiple recurrent circuits with the basal ganglia and thalamus (Alexander et al., 1986). In a computational model, Frank et al. (2001) suggest that the basal ganglia contribute a selective gating mechanism that enables flexible updating of working memory representations based on current goals. The basal ganglia have previously been shown to be involved in working memory tasks (Postle and D'Esposito, 1999; Lewis et al., 2004; Cools et al., 2008), and activity in the basal ganglia was associated with the preparation for filtering items during working memory encoding ( $\mathrm{McNab}$ and Klingberg, 2008), supporting the view that the PFC controls access to working memory via subcortical mechanisms (O'Reilly and Frank, 2006; Chatham et al., 2014). Our results that highcapacity individuals show more pronounced frontoparietal connectivity via the subcortical pathway are thus in line with the notion that individual WMC differences are partly due to differences in the efficiency with which bias signals emanating from the PFC filter irrelevant items from working memory (Rainer et al., 1998; Miller and Cohen, 2001; McNab and Klingberg, 2008).

The PPC has previously been identified as a key region for the representation of working memory items (Todd and Marois, 2005; Palva et al., 2010). Activity in the PPC is closely linked to the amount of stored information (Todd and Marois, 2004; Vogel and Machizawa, 2004) and was found to be higher in correct compared with incorrect maintenance delays (Pessoa et al., 2002). Further, working memory training has been shown to increase white matter connectivity in the parietal cortex (Takeuchi et al., 2010). In sum, our results indicate that PFC and PPC interact via two distinct anatomical pathways: a direct, corticocortical pathway and an indirect, subcortical pathway. Different cognitive aspects of WMC, according to our data, are linked to the differential involvement of these two pathways.

\section{Theoretical implications and future directions}

In many models of working memory (e.g., Rowe et al., 2000; Baddeley, 2003; Curtis and D'Esposito, 2003), the PFC is not conceptualized as a region for the storage of memory representations but rather as a source of top-down biasing control over posterior and sensory regions that actually represent the to-be-stored information (Miller and Desimone, 1994; Curtis and D'Esposito, 2003; Vogel and Machizawa, 2004; Pasternak and Greenlee, 2005; Palva et al., 2010). In this view, the PFC boosts memory representations in posterior areas via excitatory input (Edin et al., 2009) to rehearse and to keep to-be-remembered items in an activated state. This mechanism is also thought to guard items against distraction and allows for stable working memory representations (Sakai and Passingham, 2003; Edin et al., 2009). At the same time, the PFC, in orchestra with subcortical regions, exerts attentional updating and filtering processes to free occupied capacity from irrelevant information (Curtis and D'Esposito, 2003; Vogel et al., 2005; McNab and Klingberg, 2008).

Although the neural code that underlies these boosting and filtering processes is not yet sufficiently understood, our results imply a differential role of corticocortical and subcortical pathways for individual differences in WMC. Our results suggest that the two structural pathways are associated with different functions with regard to boosting and filtering processes. In terms of neural code, the corticocortical frontoparietal pathway could be responsible for boosting memory representations, whereas the subcortical pathway, via basal ganglia and thalamus, would constitute a flexible gating mechanism that is critical both for filtering irrelevant information and for updating WM with novel contents. During a complex working memory task, as used in Study 1 of the present study, these two mechanisms would need to work closely together to achieve optimal performance, as participants were required to store new items, update existing ones, and rehearse nonupdated items on each trial. However, the precise subcortical pathways influencing frontoparietal interactions are not well understood. Although the frontal lobe is considered the main cortical target of basal ganglia outputs (Alexander et al., 1986), Clower et al. (2005) found that the substantia nigra also targets the PPC. 
A

Study $1(N=70)$

WM task with updating

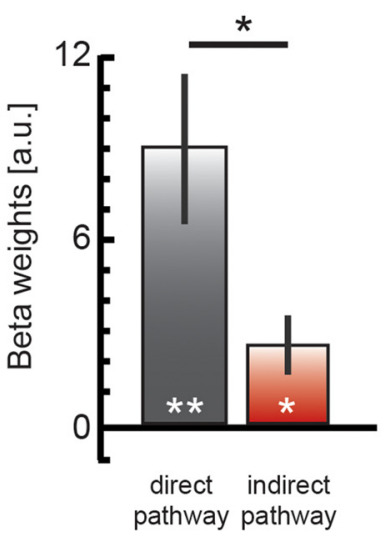

Study $2(N=109)$

WM task without updating

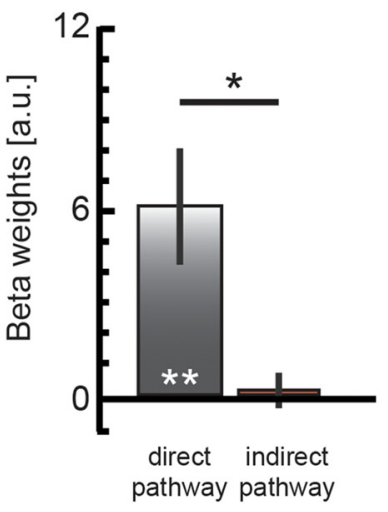

B

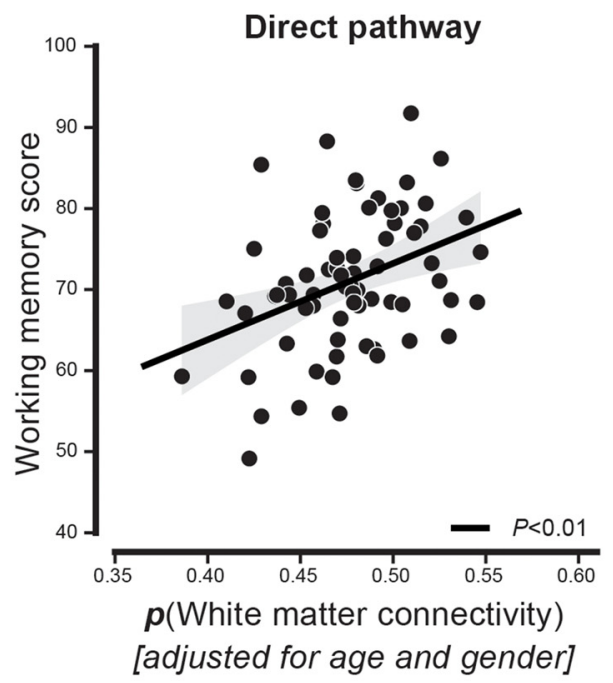

Study $1(\mathrm{~N}=70)$

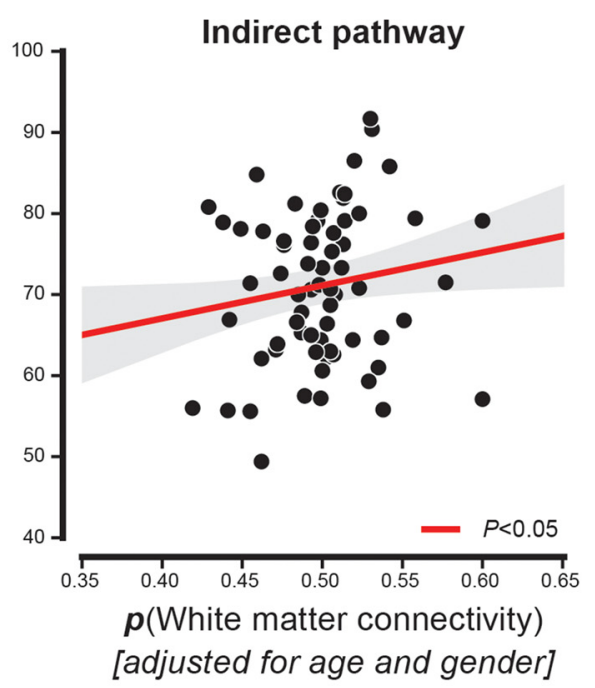

Study $2(N=109)$
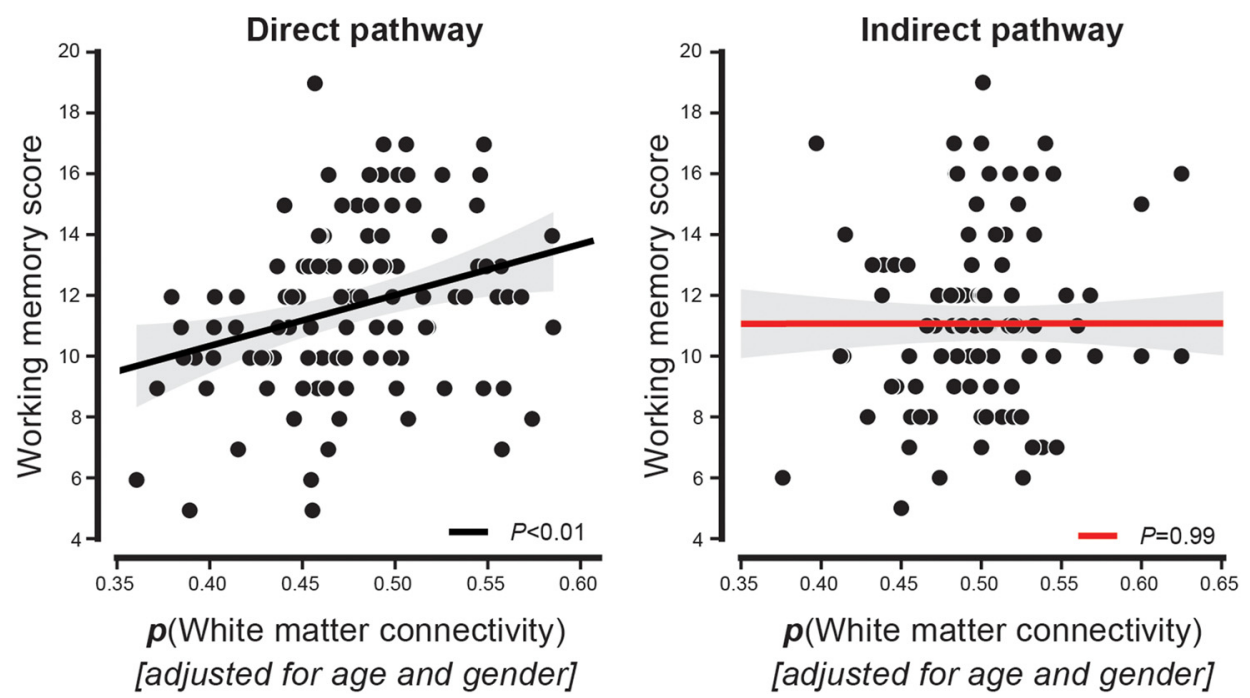

Figure 5. Dissociating different roles of the direct and indirect pathway for WMC. $A$, Results of the regression analysis linking frontoparietal connectivity to individual WMC showed a significant contribution of the direct and indirect pathway in Study 1 (top). In Study 2, only the direct pathway was a significant predictor of individual WMC (bottom). B, Scatter plots representing the relationship of connectivity estimates with working memory scores for Study 1 (top) and Study 2 (bottom). Straight lines indicate the best linear fit. Gray shaded areas represent the $95 \%$ confidence intervals. Error bars indicate SEM. ${ }^{*} P_{\mathrm{FDR}}<0.05 .{ }^{* *} P_{\mathrm{FDR}}<0.01$.

Following this argument, individual performance in simple WM tasks, as in Study 2 of the present study, that only require the storage and rehearsal of new information (Nagy et al., 2004; Karlsgodt et al., 2008; Takeuchi et al., 2010), might profit from strong, direct, frontoparietal connections, whereas performance in complex working memory tasks that also require the flexible updating of working memory contents depends to a greater extent on subcortically mediated attentional selection and filtering processes (Conway et al., 2005).

Although this interpretation finds some initial support from computational models (Frank et al., 2001), it is still an open question whether the PFC is also involved in maintaining items or solely focused on executive components, such as the aforementioned filtering processes (Rowe et al., 2000; Curtis and D'Esposito, 2003). Furthermore, deciphering the neuronal code that is potentially associated with these distinct pathways is a challenging direction for future studies. In that respect, studying the structure of anatomical networks is limited in its functional interpretation. The present results can inform existing models of WMC about the differential role of white matter tracts for frontoparietal connectivity; however, all speculations about their functional properties have to be validated using functional imaging techniques, such as EEG/MEG or fMRI. Still, given the difficulties of investigating direct versus indirect modulations with, for instance, fMRI (Smith et al., 2011), we see our results as a significant contribution to a better understanding of the neurobiological underpinnings of individual differences in WMC.

Most previous studies that have investigated white matter contributions to individual WMC differences focused on local white matter integrity of individual regions (Olesen et al., 2003; Nagy et al., 2004). For the results reported here, it has been crucial to apply a network approach to investigate how these regions are 
interconnected. Although previous studies revealed that white matter integrity of the frontal cortex is positively correlated with individual WMC (Nagy et al., 2004), we see it as an important achievement of our study to conceptualize these white matter properties as differences in the connectivity with other brain regions. Importantly, these findings integrate nicely with existing working memory models (Frank et al., 2001; O’Reilly and Frank, 2006) and might prospectively help to demarcate WMC from closely related concepts, such as general intelligence, for which the frontal connectivity pattern has been shown to be rather global in its origin and to involve a large network of other brain regions (Cole et al., 2012).

However, one might argue that the network approach chosen here comes with the cost of added complexity. Studies that investigated structural network metrics (such as the degree centrality measure used here) with respect to their physiological plausibility are scarce, which in turn limits their interpretability (Jbabdi et al., 2013; Johansen-Berg, 2013). In addition, it is not yet well understood how certain parameters of the network analysis, such as the choice of network nodes (Fornito et al., 2013) or different network metrics (Ekman et al., 2012), influence the results. In light of this, we argue that future studies might profit from combining network analyses with well-established analysis methods. In the current study, the degree centrality metric was only used in a first step to identify regions that were predictive of individual WMC. All subsequent investigations of differential PFC connectivity followed more conventional analysis methods. However, future studies will have to show whether there are more appropriate network metrics for the study of anatomical brain networks (Passingham, 2013; for similar conclusions, see Johansen-Berg, 2013). A potential shortcoming of our study is that independent populations of participants performed the two WM tasks. Therefore, we cannot exclude the possibility that systematic differences between the populations in variables not measured might have had some influence on the results. However, the populations were well matched in terms of relevant demographic variables, and our analyses show that the distributions of white matter connectivity estimates are very similar across populations. This issue is further mitigated by the relatively large sample sizes in both studies.

In conclusion, our data demonstrate that differences in WMC can be reliably predicted from white matter network connectivity. The identified differences in the anatomical circuitry highlight an important dissociation between subcortical and corticocortical pathways for frontoparietal connectivity and are in line with the attentional filtering account of WMC.

\section{References}

Alexander GE, DeLong MR, Strick PL (1986) Parallel organization of functionally segregated circuits linking basal ganglia and cortex. Annu Rev Neurosci 9:357-381. CrossRef Medline

Baddeley A (2003) Working memory: looking back and looking forward. Nat Rev Neurosci 4:829-839. CrossRef Medline

Behrens TE, Woolrich MW, Jenkinson M, Johansen-Berg H, Nunes RG, Clare S, Matthews PM, Brady JM, Smith SM (2003) Characterization and propagation of uncertainty in diffusion-weighted MR imaging. Magn Reson Med 50:1077-1088. CrossRef Medline

Cao Q, Shu N, An L, Wang P, Sun L, Xia MR, Wang JH, Gong GL, Zang YF, Wang YF, He Y (2013) Probabilistic diffusion tractography and graph theory analysis reveal abnormal white matter structural connectivity networks in drug-naive boys with attention deficit/hyperactivity disorder. J Neurosci 33:10676-10687. CrossRef Medline

Chatham CH, Frank MJ, Badre D (2014) Corticostriatal output gating during selection from working memory. Neuron 81:930-942. CrossRef Medline
Clower DM, Dum RP, Strick PL (2005) Basal ganglia and cerebellar inputs to 'AIP.' Cereb Cortex 15:913-920. CrossRef Medline

Cohen JD, Perlstein WM, Braver TS, Nystrom LE, Noll DC, Jonides J, Smith EE (1997) Temporal dynamics of brain activation during a working memory task. Nature 386:604-608. CrossRef Medline

Cole MW, Yarkoni T, Repovs G, Anticevic A, Braver TS (2012) Global connectivity of prefrontal cortex predicts cognitive control and intelligence. J Neurosci 32:8988-8999. CrossRef Medline

Conway AR, Kane MJ, Engle RW (2003) Working memory capacity and its relation to general intelligence. Trends Cogn Sci 7:547-552. CrossRef Medline

Conway AR, Kane MJ, Bunting MF, Hambrick DZ, Wilhelm O, Engle RW (2005) Working memory span tasks: a methodological review and user's guide. Psychon Bull Rev 12:769-786. CrossRef Medline

Cools R, Gibbs SE, Miyakawa A, Jagust W, D’Esposito M (2008) Working memory capacity predicts dopamine synthesis capacity in the human striatum. J Neurosci 28:1208-1212. CrossRef Medline

Courtney SM, Petit L, Maisog JM, Ungerleider LG, Haxby JV (1998) An area specialized for spatial working memory in human frontal cortex. Science 279:1347-1351. CrossRef Medline

Cowan N (2001) The magical number 4 in short-term memory: a reconsideration of mental storage capacity. Behav Brain Sci 24:87-114, 2001; discussion 114-185. Medline

Curtis CE, D'Esposito M (2003) Persistent activity in the prefrontal cortex during working memory. Trends Cogn Sci 7:415-423. CrossRef Medline

de Reus MA, van den Heuvel MP (2013) Estimating false positives and negatives in brain networks. Neuroimage 70:402-409. CrossRef Medline

Derrfuss J, Brass M, Neumann J, von Cramon DY (2005) Involvement of the inferior frontal junction in cognitive control: meta-analyses of switching and Stroop studies. Hum Brain Mapp 25:22-34. CrossRef Medline

D’Esposito M, Detre JA, Alsop DC, Shin RK, Atlas S, Grossman M (1995) The neural basis of the central executive system of working memory. Nature 378:279-281. CrossRef Medline

Edin F, Klingberg T, Johansson P, McNab F, Tegnér J, Compte A (2009) Mechanism for top-down control of working memory capacity. Proc Natl Acad Sci U S A 106:6802-6807. CrossRef Medline

Ekman M, Derrfuss J, Tittgemeyer M, Fiebach CJ (2012) Predicting errors from reconfiguration patterns in human brain networks. Proc Natl Acad Sci U S A 109:16714-16719. CrossRef Medline

Engle RW, Kane MJ (2004) Executive attention, working memory capacity, and a two-factor theory of cognitive control. Psychol Learn Motiv 44:145199.

Fornito A, Zalesky A, Breakspear M (2013) Graph analysis of the human connectome: promise, progress, and pitfalls. Neuroimage 80:426-444. CrossRef Medline

Frank MJ, Loughry B, O’Reilly RC (2001) Interactions between frontal cortex and basal ganglia in working memory: a computational model. Cogn Affect Behav Neurosci 1:137-160. CrossRef Medline

Fukuda K, Awh E, Vogel EK (2010) Discrete capacity limits in visual working memory. Curr Opin Neurobiol 20:177-182. CrossRef Medline

Fuster JM (1990) Inferotemporal units in selective visual attention and short-term memory. J Neurophysiol 64:681-697. Medline

Goldman-Rakic PS (1996) Regional and cellular fractionation of working memory. Proc Natl Acad Sci U S A 93:13473-13480. CrossRef Medline

Gong G, Rosa-Neto P, Carbonell F, Chen ZJ, He Y, Evans AC (2009) Ageand gender-related differences in the cortical anatomical network. J Neurosci 29:15684-15693. CrossRef Medline

Jbabdi S, Sotiropoulos SN, Behrens TE (2013) The topographic connectome. Curr Opin Neurobiol 23:207-215. CrossRef Medline

Johansen-Berg H (2013) Human connectomics: what will the future demand? Neuroimage 80:541-544. CrossRef Medline

Johnson MK, McMahon RP, Robinson BM, Harvey AN, Hahn B, Leonard CJ, Luck SJ, Gold JM (2013) The relationship between working memory capacity and broad measures of cognitive ability in healthy adults and people with schizophrenia. Neuropsychology 27:220-229. CrossRef Medline

Jonides J, Smith EE, Koeppe RA, Awh E, Minoshima S, Mintun MA (1993) Spatial working memory in humans as revealed by PET. Nature 363: 623-625. CrossRef Medline

Kane MJ, Engle RW (2002) The role of prefrontal cortex in workingmemory capacity, executive attention, and general fluid intelligence: 
an individual-differences perspective. Psychon Bull Rev 9:637-671. CrossRef Medline

Karlsgodt KH, van Erp TG, Poldrack RA, Bearden CE, Nuechterlein KH, Cannon TD (2008) Diffusion tensor imaging of the superior longitudinal fasciculus and working memory in recent-onset schizophrenia. Biol Psychiatry 63:512-518. CrossRef Medline

Klingberg T (2006) Development of a superior frontal-intraparietal network for visuo-spatial working memory. Neuropsychologia 44:21712177. CrossRef Medline

Lewis SJ, Dove A, Robbins TW, Barker RA, Owen AM (2004) Striatal contributions to working memory: a functional magnetic resonance imaging study in humans. Eur J Neurosci 19:755-760. CrossRef Medline

Lohmann G, Margulies DS, Horstmann A, Pleger B, Lepsien J, Goldhahn D, Schloegl H, Stumvoll M, Villringer A, Turner R (2010) Eigenvector centrality mapping for analyzing connectivity patterns in fMRI data of the human brain. PLoS One 5:e10232. CrossRef Medline

Luck SJ, Vogel EK (2013) Visual working memory capacity: from psychophysics and neurobiology to individual differences. Trends Cogn Sci 17: 391-400. CrossRef Medline

McNab F, Klingberg T (2008) Prefrontal cortex and basal ganglia control access to working memory. Nat Neurosci 11:103-107. CrossRef Medline

Miller EK, Cohen JD (2001) An integrative theory of prefrontal cortex function. Annu Rev Neurosci 24:167-202. CrossRef Medline

Miller EK, Desimone R (1994) Parallel neuronal mechanisms for shortterm memory. Science 263:520-522. CrossRef Medline

Nagy Z, Westerberg H, Klingberg T (2004) Maturation of white matter is associated with the development of cognitive functions during childhood. J Cogn Neurosci 16:1227-1233. CrossRef Medline

Nee DE, Brown JW, Askren MK, Berman MG, Demiralp E, Krawitz A, Jonides J (2013) A meta-analysis of executive components of working memory. Cereb Cortex 23:264-282. CrossRef Medline

Olesen PJ, Nagy Z, Westerberg H, Klingberg T (2003) Combined analysis of DTI and fMRI data reveals a joint maturation of white and grey matter in a fronto-parietal network. Brain Res Cogn Brain Res 18:48-57. CrossRef Medline

O’Reilly RC, Frank MJ (2006) Making working memory work: a computational model of learning in the prefrontal cortex and basal ganglia. Neural Comput 18:283-328. CrossRef Medline

Palva JM, Monto S, Kulashekhar S, Palva S (2010) Neuronal synchrony reveals working memory networks and predicts individual memory capacity. Proc Natl Acad Sci U S A 107:7580-7585. CrossRef Medline

Passingham RE (2013) What we can and cannot tell about the wiring of the human brain. Neuroimage 80:14-17. CrossRef Medline

Pasternak T, Greenlee MW (2005) Working memory in primate sensory systems. Nat Rev Neurosci 6:97-107. CrossRef Medline

Pessoa L, Gutierrez E, Bandettini P, Ungerleider L (2002) Neural correlates of visual working memory: fMRI amplitude predicts task performance. Neuron 35:975-987. CrossRef Medline

Postle BR, D’Esposito M (1999) Dissociation of human caudate nucleus activity in spatial and nonspatial working memory: an event-related fMRI study. Brain Res Cogn Brain Res 8:107-115. CrossRef Medline

Rainer G, Asaad WF, Miller EK (1998) Memory fields of neurons in the primate prefrontal cortex. Proc Natl Acad Sci U S A 95:15008-15013. CrossRef Medline

Rottschy C, Langner R, Dogan I, Reetz K, Laird AR, Schulz JB, Fox PT, Eickhoff SB (2012) Modelling neural correlates of working memory: a coordinate-based meta-analysis. Neuroimage 60:830-846. CrossRef Medline

Rowe JB, Toni I, Josephs O, Frackowiak RS, Passingham RE (2000) The prefrontal cortex: response selection or maintenance within working memory? Science 288:1656-1660. CrossRef Medline

Sakai K, Passingham RE (2003) Prefrontal interactions reflect future task operations. Nat Neurosci 6:75-81. CrossRef Medline

Smith SM, Miller KL, Salimi-Khorshidi G, Webster M, Beckmann CF, Nichols TE, Ramsey JD, Woolrich MW (2011) Network modelling methods for FMRI. Neuroimage 54:875-891. CrossRef Medline

Takeuchi H, Sekiguchi A, Taki Y, Yokoyama S, Yomogida Y, Komuro N, Yamanouchi T, Suzuki S, Kawashima R (2010) Training of working memory impacts structural connectivity. J Neurosci 30:3297-3303. CrossRef Medline

Todd JJ, Marois R (2004) Capacity limit of visual short-term memory in human posterior parietal cortex. Nature 428:751-754. CrossRef Medline

Todd JJ, Marois R (2005) Posterior parietal cortex activity predicts individual differences in visual short-term memory capacity. Cogn Affect Behav Neurosci 5:144-155. CrossRef Medline

Tzourio-Mazoyer N, Landeau B, Papathanassiou D, Crivello F, Etard O, Delcroix N, Mazoyer B, Joliot M (2002) Automated anatomical labeling of activations in SPM using a macroscopic anatomical parcellation of the MNI MRI single-subject brain. Neuroimage 15:273-289. CrossRef Medline

Vogel EK, Machizawa MG (2004) Neural activity predicts individual differences in visual working memory capacity. Nature 428:748-751. CrossRef Medline

Vogel EK, McCollough AW, Machizawa MG (2005) Neural measures reveal individual differences in controlling access to working memory. Nature 438:500-503. CrossRef Medline

Wechsler D (2009) Wechsler Individual Achievement Test, Ed 3. San Antonio, TX: Psychological Corporation.

Wilhelm O, Oberauer K (2006) Why are reasoning ability and working memory capacity related to mental speed? An investigation of stimulusresponse compatibility in choice reaction time tasks. Eur J Cogn Psychol 18:18-50. CrossRef

Zhang Y, Brady M, Smith S (2001) Segmentation of brain MR images through a hidden Markov random field model and the expectationmaximization algorithm. IEEE Trans Med Imaging 20:45-57. CrossRef Medline

Zhong S, He Y, Gong G (2015) Convergence and divergence across construction methods for human brain white matter networks: an assessment based on individual differences. Hum Brain Mapp 36:1995-2013. CrossRef Medline

Zuo XN, Ehmke R, Mennes M, Imperati D, Castellanos FX, Sporns O, Milham MP (2012) Network centrality in the human functional connectome. Cereb Cortex 22:1862-1875. CrossRef Medline 